\title{
ENTRE DUAS CULTURAS E DOIS MODELOS NOS ESPAÇOS ESCOLARES: DIÁLOGOS SOBRE A DEFICIÊNCIA
}

\author{
BETWEEN TWO CULTURES AND TWO MODELS IN SCHOOL SPACES: \\ DIALOGUES ABOUT DISABILITIES
}

\author{
Edson Mendes Júnior ${ }^{1}$ e Fernando Seffner ${ }^{2}$ \\ 1 Universidade Federal do Rio Grande do Sul, Faculdade de Educação, Brasil, E-mail: \\ edsonmsir@gmail.com, ORCID: https://orcid.org/0000-0001-9389-2885 \\ 2 Universidade Federal do Rio Grande do Sul, Faculdade de Educação, Brasil, E-mail: \\ fernandoseffner@gmail.com, ORCID: https://orcid.org/0000-0002-4580-6652
}

\begin{abstract}
ARTICLE INFO
Article history:

Received 2020-09-28

Accepted 2020-12-12

Available online 2020-12-12

Palavras-chave: Cultura escolar. Culturas juvenis. Deficiência. Modelo médico. Modelo social.

Keywords: School culture. Youth cultures. Deficiency. Medical model. Social model.

RESUMO. O artigo reflete acerca do direito à educação das pessoas com deficiência, particularmente no seu percurso escolar e nas dinâmicas de sociabilidade e possibilidades de aprendizagem. A questão da deficiência, na sua interface com a obrigatoriedade de educação escolar, tem sido tema de numerosas políticas públicas desde a Constituição Federal de 1988, mas os resultados dessas políticas ainda estão longe de mostrar um bom desempenho. Assumimos que as chances de reconhecimento e de aprendizagem derivam de complexas articulações entre quatro grandes construtos teóricos e com implicações nas práticas e modos de lidar com a deficiência: a cultura escolar, as culturas juvenis, o modelo médico e o modelo social da deficiência. $O$ artigo apresenta esses quatro construtos, discutindo suas origens e configurações de modo breve, e os toma como ferramentas para ajudar a pensar diretrizes educacionais inclusivas. A partir de cenas oriundas de projetos de pesquisa que realizaram etnografia em escolas, ensaia considerações sobre as possibilidades de inclusão de pessoas com deficiência nas trajetórias escolares.
\end{abstract}

\begin{abstract}
The article reflects on the right to education of people with disabilities, particularly in their school career and in the dynamics of sociability and learning possibilities. The issue of disability, in its interface with the mandatory school education, has been the subject of numerous public policies since the Federal Constitution of 1988, but the results of these policies are still far from showing a good performance. The chances of recognition and learning for people with disabilities stem from complex articulations between four major conceptual fields and with implications for the practices and ways of dealing with disabilities: school culture, youth cultures, the medical model and the social model of deficiency. The article presents these four constructs, briefly discussing their origins and configurations, and takes them as tools to help think about inclusive educational guidelines. Based on scenes from research projects that carried out ethnography in schools, she rehearses considerations about the possibilities of including people with disabilities in school trajectories.
\end{abstract}




\section{Produzindo pessoas e modos de aprender}

Existir é muito mais do que existir biologicamente. É existir socialmente. Existir implica reconhecimento, o que é algo que deriva de uma interação complexa entre a aceitação pelos pares, os registros simbólicos da cultura em geral e das diferentes culturas particulares, bem como dos modelos que explicam o social e que têm aceitação científica entre nós. Nesse artigo, damos continuidade a reflexões acerca do direito à educação das pessoas com deficiência, particularmente no seu percurso escolar e nas dinâmicas de sociabilidade e de possibilidades de aprendizagem. Em artigo anterior (MENDES JÚNIOR e SEFFNER, 2020), a partir da etnografia de cenas do cotidiano escolar, discutimos os diferentes desfechos de situações nas quais interagiam dois marcadores sociais da diferença, a saber, as questões da ordem da sexualidade e aquelas da ordem da deficiência. Mostramos que o pânico moral que em geral acompanha a manifestação de desejos eróticos por parte de jovens com deficiência na trajetória escolar não tem razão de ser, e que a equação desses dois marcadores pode produzir desfechos de ampliação das experiências de inclusão social. Mostramos a importância de se compreender os diferentes modos pelos quais o corpo de jovens deficientes é lido pelos pares, e apontamos que a deficiência deve ser vista como mais uma forma de se viver e experienciar o corpo biológico.

No presente texto, seguimos problematizando a presença das pessoas com deficiência no espaço escolar, e assumimos que as chances de reconhecimento e de aprendizagem estão implicadas pela negociação entre quatro grandes construtos, a cultura escolar, as culturas juvenis, o modelo médico e o modelo social da deficiência. Portanto, nos ocuparemos aqui de definir esses quatro construtos conceituais, de cuja compreensão pode decorrer - ou não - a produção de estratégias educativas de inclusão das pessoas com deficiência. Para além de apresentar os conceitos, referimos algumas cenas da vida escolar que ilustram nossos propósitos. Assumimos que a escola é um espaço público, local de experiência de afetos políticos, aqueles afetos que ampliam a compreensão de que todos e todas somos seres precários, e necessitamos de redes de solidariedade para muito além daquelas ditadas pelos laços familiares ou amorosos. Um espaço público solidário é a base de uma sociedade inclusiva.

Da análise da história é possível depreender que o tratamento dispensado às pessoas com deficiência passou, ao longo dos anos, da marginalização para o assistencialismo e, consequentemente, deste para questões envolvendo os processos educativos, a reabilitação, a integração e, na atualidade, a inclusão social. Contudo, desponta das páginas de nossa bibliografia que o percurso daqueles sujeitos não se constituiu de forma linear. Ao contrário, 
aquelas etapas, em certa medida, coexistiram e deram os contornos à forma como a medicina relacionou a deficiência às questões de saúde; à maneira como a sociedade tratou e trata os assuntos pertinentes às pessoas com deficiência; e às políticas públicas inerentes aos indivíduos com aquelas características.

No que tange à educação, nos últimos 55 anos, foi possível identificar na política educacional brasileira uma considerável sucessão de dispositivos normativos que, principalmente nas duas últimas décadas, possibilitou a implementação de políticas públicas no sentido de ampliar o acesso à educação. Isso envolveu garantir a permanência e as condições de aprendizagem aos alunos com deficiência - aspectos que conferiram à educação especial uma posição de destaque no cenário da política nacional, visto que, historicamente, essa modalidade ocupou um papel secundário no que se refere aos investimentos e ações por parte do poder público. Desse modo, antes de assumir os atuais contornos, a educação especial no Brasil trilhou um longo caminho, contando com mudanças referentes à concepção de deficiência e, consequentemente, com a emergência de políticas orientadas à garantia da escolarização de pessoas com deficiência em unidades do ensino comum (MENDES JÚNIOR, 2013; MENDES JÚNIOR e TOSTA, 2012; SILVA JÚNIOR e BAPTISTA, 2012).

Nesse tocante, cabe-nos analisar como os modelos médico e social de deficiência incidem no âmbito escolar, uma vez que a referida instituição se constitui com base em uma cultura que subdivide os programas ou parâmetros oficiais de ensino em finalidade e em resultado da ação educativa. Esses modelos não atuam de modo direto ou mecânico no ambiente escolar. Eles dialogam, modificam e são modificados pela cultura escolar e pelas negociações com as culturas juvenis. É frequente que escutemos, de professores e professoras, alunos e alunas, opiniões que revelam fragmentos desses modelos, retrabalhados pelos valores e práticas da cultura escolar e das culturas juvenis. Por conta disso, é importante conhecer os principais elementos da história e da constituição de cada um dos modelos.

\section{Dos $\operatorname{corpos}^{1}$ marcados pelo patológico à constituição dos sujeitos de direito}

De acordo com alguns autores (PESSOTTI, 1984, entre outros), o discurso religioso foi provavelmente o primeiro a projetar hipóteses sobre a causalidade da deficiência, descrevendo-a como resultado de castigos ou de milagres divinos. Tal raciocínio promoveu o fazer da assistência aos deficientes práticas de redenção e caridade, uma vez que a concepção religiosa compreendia a deficiência como um problema teológico e moral (SANTOS, 2010, p. 80). A partir do século XIX, sob a égide das narrativas modernas, o modelo

${ }^{1} \mathrm{O}$ termo corpo está sendo utilizado aqui no sentido de corpo biológico. 
médico emerge de maneira a retirar a deficiência da autoridade religiosa. Entretanto, somente ao final da primeira grande guerra mundial, mais precisamente no século $X X$, pôde-se vislumbrar a consolidação de tal modelo. Em linhas mais gerais, as pessoas vitimizadas pela guerra, ao apresentarem algum tipo de mutilação, demandaram atendimentos específicos, o que deslocou a deficiência da condição espiritual à condição médica. O leque de deficiências se ampliou, englobando manifestações físicas e mentais, derivadas do trauma dos longos anos de guerra. Assim, sendo, o modelo médico centrou sua ação na reabilitação dos distintos sujeitos. Com isso, tal modelo visava as suas reinserções no convívio social, e particularmente no mundo do trabalho. A pessoa com deficiência - vista como anormal - deveria ser curada, tornando-se capaz de produzir e viver em sociedade (MELO, 2019).

Segundo Santos (2010), desde a ascensão do modelo médico, o corpo nomeado deficiente começou a ser, invariavelmente, "catalogado como uma variação indesejada e patológica do corpo considerado normal" (SANTOS, 2010, p. 80). Portanto, sob os auspícios de tal modelo, as pessoas com deficiência passaram a ser percebidas exclusivamente pelas marcas ou traços que carregavam em seu corpo (BARBOSA-FOHRMANN, 2016; RODRIGUES, 2014; FRANÇA, 2013; SANTOS, 2010; DINIZ; BARBOSA; SANTOS, 2009; RECHINELI; PORTO; MOREIRA, 2008; GAIO, 2006). Partindo de tal premissa, compreendese que a deficiência é, frequentemente, concebida como um fenômeno que se materializa em um corpo que, ao apresentar limitações funcionais, sensoriais e intelectuais, torna-se passível à intervenção médica, portanto, à medicina curativa (FRANÇA, 2013; BAMPI; GUILHEM; ALVES, 2010; DINIZ; BARBOSA; SANTOS, 2009). Dessa forma, a deficiência fica individualizada no sujeito, é um atributo dele, e pouco diz do contexto social que o circunda. Em linhas mais gerais, na abordagem médica ou biomédica, a deficiência desponta como marca impressa na relação entre os sujeitos com deficiência e os demais supostamente "sem deficiência", que constituem, nesse linguajar "a sociedade", tomada como perfeita. Desse modo, entende-se que a deficiência, assim como afirma França (2013), ainda é apreendida como algo que se encontra no domínio de um corpo biológico que, submetido a processos de normalização, apresenta-se como algo incompleto (ALEM, 2015; FRANÇA, 2013; AUGUSTIN, 2012; GAIO, 2006; KASSAR, 2000). De um modo mais específico, o modelo médico traduz-se em uma concepção individualista ou individualizada do sujeito com deficiência.

Para França (2013), o modelo médico, ao restringir a análise da deficiência ao corpo, centra sua acepção daquela em uma alegada neutralidade científica que, baseada em pressupostos biológicos, cristaliza ações normalizadoras responsáveis por situar as pessoas com deficiência no campo da inaptidão, da perda, da falta, da doença e, grosso modo, da reabilitação. Nesse sentido, French e Depoy (2000) afirmam que, no modelo médico, a deficiência é circunscrita a algo indesejado que deve, por conseguinte, ser curado ou corrigido. 
Sobre tal aspecto, França (2013) nos diz, de maneira crítica, que o modelo médico, ao passo que enfatiza a premência da intervenção física no corpo nomeadamente deficiente, busca promover a emergência de vidas que se "aproximem de uma suposta normalidade" padronizada (FRANÇA, 2013, p. 63). Para Bampi, Guilhem e Alves (2010), aquela normalidade de que trata França (2013) diz respeito à forma como a deficiência foi e é largamente compreendia por meio daquele modelo, bem como pelo senso comum. Destarte, cabe pontuar que, de acordo com essas pesquisadoras (BAMPI; GUILHEM; ALVES, 2010), a deficiência é percebida pela sociedade como um infortúnio ou má sorte pessoal, isto é, como a expressão de limitações relacionadas a aspectos corporais e às "habilidades básicas para a vida social" (BAMPI; GUILHEM; ALVES, 2010, p. 69).

À semelhança dos autores supracitados, Diniz, Barbosa e Santos (2009) ressaltam que a opressão existente sobre o corpo com deficiência é resultante da cultura da normalidade e da produtividade. Por seu turno, tal cultura é compreendida como "uma expectativa biomédica de padrão de funcionamento da espécie", bem como um "preceito moral de produtividade e adequação às normas sociais" vigentes (SANTOS, 2009, p. 97-98). Assim sendo, Barbosa-Forhmann (2016) adverte que a tônica dada, pelo referido modelo, à forma como a pessoa com deficiência deve ser inserida na sociedade, baseia-se nas prerrogativas de uma integração sem que haja, necessariamente, a inclusão de tais sujeitos num contexto mais amplo de sociabilidade. Segundo os preceitos da integração, o sujeito com impedimentos deve empreender seus próprios esforços para adaptar-se à vida em sociedade ou, quando restrito a espaços especializados, ao convívio com os seus pares (BARBOSAFOHRMANN, 2016). Cabe-nos ressaltar que a lógica depreendida da integração é a mesma que define os contornos do modelo médico. Aqui, a deficiência é marcada pela dicotomia entre o normal e o patológico. O corpo com limitações é construído socialmente e, paulatinamente, constituído como fenômeno biológico, no qual a deficiência reside como sinônimo de incapacidade. Portanto, historicamente edificada como desvio, alteração, mazela, perda e afecção, a deficiência - submetida ao saber médico - delineou-se no contraste com uma representação do corpo saudável (BARBOSA-FOHRMANN, 2016; AUGUSTIN, 2012; BONFIM, 2009; DINIZ; BARBOSA; SANTOS, 2009).

Não obstante, é frequente, no modelo médico, a percepção de que a deficiência possui uma relação de causalidade entre os impedimentos situados no corpo da pessoa com deficiência e as desvantagens socioeconômicas imputadas a esses sujeitos (BARBOSAFOHRMANN, 2016; MELLO; NUERNBERG; BLOCK, 2014; DINIZ; BARBOSA; SANTOS, 2009). Do mesmo modo, vista como uma desvantagem natural, a deficiência torna-se sinônimo dos impedimentos que lhes são atribuídos e, consequentemente, é classificada como uma desordem que deve ser submetida à "metamorfose para a normalidade", seja essa engendrada por meio de processos de reabilitação, através de procedimentos genéticos, ou, mais comumente, por meio de práticas e ferramentas educativas (DINIZ; BARBOSA; 
SANTOS, 2009, p. 101). Em linhas mais gerais, para Diniz, Barbosa e Santos (2009), ao ter no corpo o objeto de sua exequibilidade, o modelo médico centra seu perscruto na busca de uma normalidade, na qual seja possível conferir eficácia à medicalização dos impedimentos. Contudo, reiteram esses autores que, "na ausência de possibilidades biomédicas", a educação se traduz em um mecanismo de "docilização dos corpos" (DINIZ; BARBOSA; SANTOS, 2009, p. 101-102). Assim, nesse modelo, um corpo marcadamente constituído por impedimentos:

[...] deve ser objeto de intervenção dos saberes biomédicos. Os impedimentos são classificados pela ordem médica, que descreve as lesões e as doenças como desvantagens maturais e indesejadas. Práticas de reabilitação ou curativas são oferecidas e até mesmo impostas aos corpos, com o intuito de reverter ou atenuar os sinais de anormalidade (DINIZ; BARBOSA; SANTOS, 2009, p. 101-102, grifo nosso).

Conquanto o modelo médico tenha retirado a deficiência dos auspícios religiosos, é preciso ponderar que o corpo deficiente, historicamente assinalado pelas marcas da incompletude e da perda, passou a ser arrolado, em contraposição ao corpo considerado normal, como sinônimo de patologia (SANTOS, 2010; FRENCH; DEPOY, 2000). No mesmo sentido, afirmar-se que o discurso médico ou biomédico, mesmo ao se estruturar de maneira a se sobrepor às narrativas calcadas em explicações metafísicas, continuou pautando o corpo à anormalidade. Disso denota que, à pessoa com deficiência, foi outorgado um corpo de natureza subversiva que, em contraposição com aquele concebido como normal, pôde - em tese - submeter-se à "possibilidade de tratamentos corretivos com as técnicas que a biomedicina passou a oferecer". Portanto, conforme destaca o autor, Santos (2010), foi a partir do modelo biomédico que a deficiência passou a ser mensurada em conformidade com os aspectos físicos e cognitivos situados no âmbito corpo. O que estamos ressaltando é que o pensamento centrado no modelo médico traz consigo uma definição de educação, e um conjunto de tarefas para a prática escolar, ainda manifestas em nosso ordenamento pedagógico (SANTOS, 2010, p. 84-85).

No bojo das argumentações e ponderações em torno do modelo médico, Mello, Nuernberg e Block (2014) defendem que aquele modelo centraliza sua ação na cura ou na medicalização do corpo assinalado como deficiente. Isso significa dizer que a deficiência é, geralmente, apreendida como um acaso do destino ou um incidente isolado, uma condição atípica de origem orgânica que, ao tornar-se um "fardo social que implica em gastos com reabilitação", sugere que a deficiência permanece submersa a questões assistencialistas de cunho caritativo (MELLO; NUERNBERG; BLOCK, 2014, p. 92). Nessa perspectiva, Santos (2010) considera que os efeitos da circunscrição dos corpos deficientes em processos de medicalização, além de inviabilizar a compreensão da deficiência como expressão da 
diversidade humana, fortaleceu a acepção daquela como sinônimo ou tradução do corpo anormal. Em linhas mais gerais, destaca-se que a sistemática da reabilitação, necessária à inserção das pessoas com deficiência no mercado de trabalho, passou a ser a tônica para que aqueles sujeitos pudessem ser produtivos em sintonia com as expectativas sociais construídas em torno da exultação das habilidades corporais (SANTOS, 2010; FRANÇA, 2013; DINIZ; BARBOSA; SANTOS, 2009). Assim sendo, além de Santos (2010), inúmeros autores ressaltam que, conforme a métrica do modelo médico, o corpo disfuncional é algo passível de ser curado e reabilitado (BISOL; PEGORINI; VALENTINI, 2017; MELLO; NUERNBERG; BLOCK, 2014). Paralelamente à argumentação de Santos (2010), Werneck (2004) ressalta que o modelo médico parte da premissa de que as lesões, bem como as limitações situadas no corpo, são as únicas causas dos "processos de discriminação enfrentados pelas pessoas com deficiência". Em outras palavras, não importa a forma como a sociedade lida com aqueles imperativos imputados ao corpo (lesões e limitações), uma vez que cabe à pessoa com deficiência ajustar-se à realidade na qual encontra-se imbricada (WERNECK, 2004, p. 16).

No mesmo sentido que Santos (2010), Werneck (2004) reforça que, no modelo médico, a deficiência, traduzida como experiência do corpo, deve ser "combatida" com tratamentos oriundos da área da saúde. Em resumo, Werneck (2004) pondera que a cura completa dos impedimentos situados no corpo deficiente é aventada como condição ideal ao exercício de determinados direitos, bem como aquisição de cidadania pelas pessoas com deficiência. Distintamente a Werneck (2004), para Alem (2015), o modelo médico ainda concebe a pessoa com deficiência como alguém "incapaz de exercer qualquer direito fundamental e, até mesmo, incapaz de ostentar alguns direitos" (ALEM, 2015, p. 3). Em muitos casos, da pessoa com deficiência é extirpada a capacidade de tomar decisões sobre si mesma, já que sua vontade pode ser gerida ou substituída pela de um terceiro - o que nos impele a lembrar que a muitos sujeitos com deficiência é negado o curso natural do adultecer, o que exacerba o cerceamento das famílias sobre muitos aspectos pertinentes aos impedimentos localizados no corpo daquelas pessoas. Dito isso, torna-se patente que a associação da deficiência à doença, bem como aos procedimentos de cura, além implicar aqueles indivíduos em processos de infantilização, corrobora a legitimação do encastelamento da pessoa com deficiência à esfera doméstica.

Em contraposição ao modelo médico, o modelo social de deficiência tem sua gênese entre os anos de 1960 e 1970. Resultante das discussões e críticas às limitações daquele modelo, o modelo social ascende não apenas como uma proposição eminentemente política - decorrente dos chamados Social Disability Movement ${ }^{2}$, mas como uma alternativa à

\footnotetext{
${ }^{2} \mathrm{O}$ movimento pelos direitos das pessoas com deficiência é um movimento social - de incidência global - que atua de maneira a garantir igualdade de oportunidades e direitos iguais para todas as pessoas com deficiência. Em linhas gerais, o referido movimento é composto por organizações de ativistas com e sem deficiência que trabalham em conjunto com objetivos e demandas semelhantes, tais como: acessibilidade e segurança em arquitetura, transporte e ambiente físico; direito à vida independente e à autonoma, igualdade de oportunidade no mercado de
} 
semântica, à autoridade e à hegemonia da perspectiva médica sob a deficiência (BISOL; PEGORINI; VALENTINI, 2017; MELLO; NUERNBERG; BLOCK, 2014; AUGUSTIN, 2012; BAMPI; GUILHEM; ALVES, 2010; SANTOS, 2010; DINIZ; BARBOSA; SANTOS, 2009; GAIO, 2006; WERNECK, 2004). Nesse sentido, a deficiência passou ser debatida como "uma situação de discriminação coletiva e de opressão social para a qual a única resposta apropriada" seria a "ação política" (BAMPI, GUILHEM, ALVES, 2010, p. 6).

De acordo com Santos (2010), ao possuir como cerne o campo da Sociologia, o modelo social centrou sua análise no indivíduo inserido em relações - o corpo com impedimentos deixou de ser o foco da dinâmica causal que o modelo médico geria entre deficiência e sociedade. Sendo assim, no modelo médico a deficiência é construída em contraste com a normalidade enquanto no modelo social a deficiência se materializa na relação estabelecida entre a sociedade e o sujeito com deficiência.

Em linhas gerais, a partir da perspectiva teórica delineada pelo modelo social, Santos (2010) afirma que as acepções sociológicas acerca da pessoa com deficiência promoveram a ascensão de um discurso sociopolítico. Segundo Bampi, Guilhem e Alves (2010), o corroborar a transposição da deficiência do campo da natureza à sociedade significou uma revolução paradigmática. Qual seja: a deficiência passou a ser compreendida não mais como uma questão estritamente ligada à saúde, mas como o efeito do desenvolvimento das sociedades contemporâneas (SANTOS, 2010). De maneira mais clara, Santos (2010) avulta que, por consolidar o campo de estudos sobre a deficiência, bem como compreender essa como um subproduto da desigualdade social - reflexo da dinâmica cultural e econômica que envolve distintas sociedades -, o modelo social assume proeminência como paradigma explicativo da deficiência. Logo, é salutar destacar que tal modelo fomentou o deslocamento da deficiência dos meandros da reabilitação para o campo da justiça social e dos direitos humanos:

O discurso sociológico e político que passou a reescrever a deficiência a partir dos anos 1960 começou a problematizar a deficiência como uma matéria de justiça social, pois denunciava a opressão social a que os corpos deficientes estavam submetidos em uma cultura da normalidade que privilegiava corpos não deficientes (SANTOS, 2010, p. 85).

No mesmo sentido que Santos (2010), Bampi, Guilhem e Alves (2010) reiteram que o modelo social é uma corrente teórica e política que se obtempera ao modelo médico, uma vez que retirou das pessoas com deficiência a origem da desigualdade e a devolveu para a sociedade. Acerca desse entendimento, Werneck (2004) pontua que, através do modelo

trabalho, acesso à educação inclusiva e à moradia; direito à antidiscriminação, protreção contra abusos, negligência e outras violações de direitos. Em resumo, no campo dos direitos humanos, os movimentos sociais de deficiências atuam de maneira a romper barreiras institucionais, físicas e sociais, as quais impedem pessoas com deficiência de exercerem sua cidadania. 
social, tornou-se exequível demonstrar teórica e empiricamente que a deficiência é sempre uma construção coletiva entre indivíduos e sociedade, situação mediada pelas pedagogias culturais, aquelas que derivam de artefatos culturais - filmes, propagandas, leis, imagens, declarações de autoridades, músicas, romances, livros didáticos, brinquedos etc. Portanto, poder-se-ia sugerir que há uma responsabilidade compartilhada para os casos de deficiência nos quais o sujeito encontra-se à margem da sociedade por não ser economicamente ativo. Sob a mesma perspectiva, Mello e Nuernberg (2012) advogam que, a partir do modelo social, conceber a deficiência como um fenômeno, ou como um processo que não se restringe ao corpo, ajuda-nos a reconhecer que a deficiência é um construto sociocultural, por meio do qual se estruturam os mecanismos de produção das incapacidades de natureza física, sensorial, mental ou intelectual. Sob esse aspecto, Werneck (2004) reconhece que os esforços da reabilitação e os demais tratamentos médicos, destinados às pessoas com deficiência, não devem prevalecer sobre as medidas necessárias à promoção de garantias sociais àqueles sujeitos. Isso se dá por meio do pleno exercício de seus direitos humanos e constitucionais, pela sua inclusão na vida em sociedade e pela implementação de mudanças sociais.

Entretanto, de acordo com WERNECK (2004), é importante ponderar que assumir o paradigma do modelo social como balizador das questões relativas às pessoas com deficiência "não pressupõe o abandono da reabilitação e dos tratamentos" biomédicos, bem como não significa "ignorar o quanto os avanços nessa área garantem o bem-estar às pessoas" (DINIZ; BARBOSA; SANTOS, 2009, p. 104; WERNECK, 2004, p. 2). Pelo contrário, a crítica do modelo social ao modelo médico reside na centralidade que este modelo adjudicou ao corpo, conferindo à deficiência o mesmo significado de lesão ou perda. Em outros termos, a perspectiva positivista, que reificou o modelo médico, atribuiu sentido negativo às diferenças "fisiológicas, morfológicas" e funcionais das pessoas com deficiência, em razão de uma "normatividade conceitualmente estabelecida que considerava essas diferenças como doenças ou anormalidades" (OLIVEIRA; MAIO, 2011; BISOL; PEGORINI; VALENTINI, 2010, p. 93).

Por meio do crivo do modelo social, a deficiência não é mais percebida como se fosse a manifestação de um problema a ser corrigido, tornando-se palatável à normalidade. $\mathrm{A}$ mudança, provocada por esse novo modelo, retirou as diferenças corporais, sensoriais e intelectuais do âmbito das anomalias e da patologia para ratificar que "existem diferentes formas de funcionamento de um corpo, de tal modo que não se pode predizer a existência de uma norma a todos os seres humanos" (DINIZ; BARBOSA; SANTOS, 2009, p. 98). Ou seja, nem toda pessoa com deficiência vive a experiência da deficiência (MELLO; NUERNBERG; BLOCK, 2014; SANTOS, 2010). Disso denota-se que, de acordo com Oliveira e Maio (2011), o paradigma social criou bases à compreensão de que o ser humano se constitui e é constituído sempre por relações que se estabelecem entre a sociedade, a cultura e a história, 
ou seja, relações micro e macrossistêmicas que não permitem a apreensão do ser humano de forma isolada e individualizada.

No campo político, Bampi, Guilhem e Alves (2010) salienta que, ao restringirem a identificação da deficiência apenas aos aspectos corporais dos indivíduos, as pesquisas e as políticas públicas, voltadas às pessoas com deficiência, reforçavam os imperativos sociais responsáveis por limitar a "expressão das capacidades e potencialidades daqueles sujeitos". Desse modo, a adoção do modelo social exacerbou a necessidade de ambos os campos político e científico - compreenderem a deficiência como um fato social para além do corpo. Logo, argumentam que, por se tratar de um fenômeno sociológico e "não algo determinado pela natureza", a resolução de questões envolvendo a deficiência "não deveria estar centrada na terapêutica, mas na política" (BAMPI; GUILHEM; ALVES, 2010, p. 6 - 8). De um ponto de vista mais amplo, Werneck (2004) disserta que o modelo social conclama as famílias, os profissionais da saúde e da educação, o governo, os meios de comunicação e demais setores da sociedade a compreender que os tratamentos - aos quais as pessoas com deficiências são submetidas -, ainda que necessários e importantes, "não devem se sobrepor à garantia de educação, de emprego, de cultura, de lazer e de vida independente para as pessoas com deficiência" (WERNECK, 2004, p. 3). Igualmente, sob o mesmo plano analítico, Bampi, Guilhem e Alves (2010) destacam que, por meio da consolidação do modelo social, a cura do corpo com impedimentos deixou de ser a busca e a essência do tratamento dispensado às pessoas com deficiência. Conforme assinalam as pesquisadoras, nesse modelo não há distinção entre doença e deficiência, porquanto, ao separar essa da lesão, pôde-se evidenciar os aspectos envolvidos na "experiência da exclusão" e da "restrição social" sofridas por aqueles classificados como deficientes (BAMPI; GUILHEM; ALVES, 2010, p. 7-8).

Sob a mesma ótica, Diniz, Barbosa e Santos (2009) destacam que, com a ascensão do modelo social, foi possível vislumbrar que o discurso médico, por meio da cultura da normalidade, reforçou a discriminação e a opressão das pessoas com deficiência. A construção ideológica da figura do incapacitado incidiu diretamente nos processos de discriminação daqueles sujeitos, o que restringiu, e ainda restringe, a sua plena participação nas distintas esferas da vida em sociedade. No bojo dessa argumentação, Santos (2010) destaca que o modelo social alvitrou a possibilidade de que nem todos os sujeitos com impedimentos sofreriam a opressão advinda da deficiência. Nesse sentido, como base no referido modelo, Santos (2010) avulta que a desigualdade social é engendrada a partir da valoração do corpo com impedimento, que, conquanto traduza-se na expressão da diversidade humana (SANTOS, 2010), cristalizou-se como "um produto de uma sociedade descapacitante ou incapacitante", e não como resultado de uma "patologia no corpo do indivíduo" (BISOL; PEGORINI; VALENTINI, 2017, p. 94). Em síntese, foi por meio do modelo médico que a deficiência passou a ser abarcada como uma experiência de desigualdade que, 
via de regra, não faz distinção entre os sujeitos com diferentes tipos de impedimentos, mas Ihes imputa a necessidade de empreenderem esforços para que seja viável sua adaptação à sociedade (BARBOSA-FOHRMANN, 2016; MELLO; NUERNBERG; BLOCK, 2014; DINIZ; BARBOSA; SANTOS, 2009). A essa lógica, já citada anteriormente e vinculada ao modelo médico, foi dada o nome de integração, a qual, por muitas décadas, norteou as políticas públicas destinadas às pessoas com deficiência no Brasil.

Contrariamente àquela perspectiva, o modelo social deslocou o acento da deficiência, que encontrava-se no sujeito, e o transferiu à sociedade. Portanto, conforme descreve Barbosa-Fohrmann (2016), o modelo social permitiu a transposição do tema da deficiência dos "espaços domésticos para a vida pública" (BARBOSA-FOHRMANN, 2016, p. 104). Dito isso, reitera-se que, sob o prisma da perspectiva social, é a sociedade que deve adaptar-se aos sujeitos com impedimentos, eliminando as barreiras que impedem a acessibilidade e repensando o sentido da adaptação. Segundo alguns pesquisadores, quando a gênese da deficiência passa a situar-se na sociedade, em decorrência da análise paradigmática do modelo social, reconhece-se que as pessoas com deficiência são sujeitos de direito e que a desvantagem social, vivenciada por aqueles indivíduos, "não é uma sentença da natureza, mas o resultado de um movimento discursivo da cultura da normalidade que descreve os impedimentos corporais como abjetos à vida social" (DINIZ; BARBOSA; SANTOS, 2009, p. 108). Portanto, ao passo que no modelo médico a deficiência é comumente associada ao fenômeno do corpo, no qual a ausência de membros ou a presença de limitações funcionais tornam-se elementos definidores do sujeito (BARBOSA-FOHRMANN, 2016; DINIZ; BARBOSA; SANTOS, 2009), no modelo social, os impedimentos são concebidos como uma das formas de se viver e experienciar o corpo biológico.

É necessário pontuar que o modelo médico ou biomédico de deficiência coexiste e, em muitos casos, complementa o modelo social no sentido de fomentar ações integradas destinadas à promoção e à proteção dos direitos das pessoas com deficiência. Tal coexistência se reflete, por exemplo, nas políticas públicas de redistribuição de renda como o Benefício de Prestação Continuada (BPC). Reforça-se que, embora o modelo social de deficiência seja uma elaboração essencialmente sociológica, em sua concepção teórica e prática não se ignora a importância da medicina na vida dos indivíduos com impedimentos. 0 que se questiona, sobretudo, é o crescente processo de medicalização do corpo categorizado como deficiente. Sendo assim, ao considerarmos o modelo social em oposição ao modelo médico, partimos do pressuposto de que o paradigma sociológico reconhece que a deficiência é resultante das interações pessoais e socioambientais estabelecidas entre o sujeito com impedimentos e o meio no qual se encontra imbricado. Isto é, defende-se a premissa de que "as experiências de opressão vivenciadas pelas pessoas com deficiência" não residem na lesão ou no corpo lesionado, "mas na estrutura social incapaz de responder à diversidade" e "à variação corporal humana” (MELLO; NUERNBERG, 2012, p. 638). 


\section{Deficiência, cultura escolar e culturas juvenis}

Todos e todas carregamos elementos dos dois modelos acima mencionados em nossos modos de perceber a deficiência. Vemos uma senhora em uma cadeira de rodas e percebemos que ela não conseguirá subir os três degraus que separam a calçada da entrada da loja onde deseja ir. Ela é a deficiente. Os outros clientes da loja são os normais. Vemos a mesma senhora, frente a mesma loja, subindo com a cadeira de rodas por uma rampa, e ingressando na loja. Ela não é uma deficiente, pelo menos não naquele momento, entrou na loja assim como as demais pessoas, por obra própria. Onde está a deficiência? Na senhora da cadeira de rodas ou na loja que não providenciou a instalação da rampa? Quantos e quantas de nós não conseguiríamos fazer algumas coisas se não tivéssemos alguma prótese, tutorial, auxílio, estrutura de apoio? Você que está lendo esse texto tem certeza que poderia mastigar tudo que quer mastigar se não tivesse alguma prótese dentária? Na vida escolar, são muitas as situações nas quais fragmentos dos dois modelos dialogam, em particular quanto isso acontece:

Escola de grande porte, exclusiva de ensino médio, situada próxima do centro de Porto Alegre, na esquina de duas importantes avenidas, e que recebe alunos e alunas de muitos bairros da cidade. Já pela terceira vez nesse semestre vou supervisionar estagiários lá, e aproveito para circular pelos espaços, conversar com o alunado, colher impressões. Nas duas primeiras visitas, chamou-me a atenção o empenho dos alunos em subir duas meninas cadeirantes, que eram trazidas para estudar por uma viatura do serviço social da prefeitura. Comentei o caso com as professoras da escola, que me informaram que nem era necessário pedir ajuda, assim que as duas desciam com a cadeira na rampa da viatura para a calçada, alunos e alunas se ofereciam para ajudar a levar para cima, vencendo os cinco largos degraus que separam o portão principal do nível da rua. A escola tem outra entrada, pelo lado, para carros, mas, do mesmo modo, ali há que subir uma escadaria, que é mais íngreme e mais estreita. Por sorte, na terceira visita à escola cheguei no momento em que as meninas foram deixadas na calçada, e pela primeira vez subiram por uma rampa muito engenhosa, que aproveita os largos degraus, e sobe em zigue-zague. Mesmo com a rampa, alunos ajudaram a empurrar as cadeiras, e festejaram, tirando até mesmo fotos com o celular. A felicidade das duas meninas era grande. Uma delas disse que ia sentir falta de ser carregada pelos guris, que isso a deixava feliz. Houve risos e zoações, num clima muito alegre. No meio de tudo, um 
menino gritou apontando para a rampa: "a escola tá evoluindo, tava deficiente, não é mais deficiente agora". Todo mundo riu! (Diário de campo, 2016) 3

Mesmo sem perceber ou dar-se conta, o menino que gritou a frase operou com elementos que nos permitem pensar no modelo social da deficiência, ao referir-se à escola como agora não sendo mais deficiente. Mas talvez esse mesmo menino, em outros momentos, refira-se à deficiência com elementos do modelo médico. Haveria que situá-lo na conexão com as culturas juvenis com as quais dialoga para além de sua inserção na escola. Queremos finalizar esse artigo tecendo algumas considerações acerca dos dois modelos quando em diálogo com a cultura escolar e com as culturas juvenis que nela habitam. Partimos do clássico artigo de Dominique Julia (2001), em que a definição de cultura escolar está dada pela articulação contingente entre normas, condutas esperadas, práticas regulatórias, finalidades do ensino, modos de avaliação, expectativas da sociedade e das famílias e dos próprios alunos em torno do que se deve ou não fazer quando no interior da instituição escolar. O conceito de cultura escolar permite reconhecer os contornos dessa instituição, salientando as marcas que constituem sua identidade cultural em meio a tantas outras instituições. Mas não podemos entender a expressão identidade cultural como indicativa de algo de contornos rigorosamente fixos. Se, por um lado, quando falamos escola, um conjunto de atributos muito similares nos vêm à cabeça, servindo para designar enorme conjunto de estabelecimentos, por outro, a cultura escolar é notavelmente dinâmica. Isso acontece porque a cultura escolar diz respeito de modo muito forte a práticas em exercício, e estas acontecem sempre em disputa com os valores das culturas juvenis e com marcas dos diferentes contextos e épocas históricas. Embora comumente usada no singular, cultura escolar, optamos aqui por abrir a possibilidade de falar em culturas escolares, uma vez que o contexto de cada escola, em cada época, opera modificações importantes.

Nosso propósito é pensar que há uma interação dinâmica e muito móvel entre conceitos e valores dos dois modelos indicados - médico e social - e as culturas juvenis e as culturas escolares. As culturas juvenis constituem os pontos de apego identitário de muitos jovens, e são também muito diversas. Se tomarmos o gosto musical, um dos indicadores de pertença a essas culturas, podemos nomear as galeras funk e as galeras rap, os adeptos do K-Pop, meninas que seguem boy bands, praticantes do hip-hop, quem pertence a grupos de música e dança tradicionalista, aqueles e aquelas fãs do rock, da música sertaneja, do sertanejo universitário, da música eletrônica, fãs de determinados cantores nacionais ou internacionais, integrantes de círculos da música gospel, numa infinidade de posições de sujeito, sempre móveis, sempre em tensão com outras. Mais do que simples gostos musicais, a adesão a bandas, cantores e cantoras, ritmos e movimentos musicais vem carregada de

\footnotetext{
${ }^{3}$ Diário de campo do projeto de pesquisa Investigação das aprendizagens de estagiários na produção de atividades didáticas e na relação com as culturas juvenis a partir dos relatórios de estágio docente em Ensino de História, mantido pelo segundo autor desse artigo. Maiores informações em http://lattes.cnpq.br/2541553433398672.
} 
valores morais, éticos e políticos. Para além das políticas públicas já citadas acima, que definem contornos do que sejam os procedimentos para compreender a deficiência, no interior de cada escola a disputa por significados se estabelece, em particular desde o momento em que a legislação brasileira tomou medidas de inclusão das pessoas com deficiência nas escolas regulares, estimulando o convívio:

Segunda-feira, dia quente, adentrei, pela primeira vez, a sala de aula da turma que iria acompanhar durante os meses seguintes. A professora regente me apresentou como pesquisador da universidade, sentei-me aos fundos. Na sala, havia uma pluralidade de jovens e adultos - em sua maioria, trabalhadores que buscavam no ensino noturno uma melhor colocação no mercado do trabalho. A escola está localizada em um terreno cedido pela universidade, e de onde se avistam os prédios de algumas faculdades, em bairro popular distante do centro da cidade. Contudo, fui tomado de espanto quando percebi que eles não sabiam da existência e da gratuidade da universidade. Transcorrido o primeiro período, antes do intervalo, a professora me chamou até sua mesa e começou a falar sobre os diferentes grupos que compunham a turma. Usava termos como "aquele é muito inteligente, mas não quer nada como nada". Em uma dada aula, ao se referir a uma aluna com deficiência, a professora chegou a me dizer o seguinte: "Essa aí [aluna] não vai aprender mesmo... É só passar!". O peso que essa fala carregava evidenciou muitas coisas, mas a mais significativa foi o desrespeito com a diferença - que se traduzia no descaso e abandono da aluna pela professora, o que era reforçado pela crença de que essa aluna não estava apta à escolarização. A partir desse episódio, comecei a me questionar sobre a política de formação de professores para esse grupo de sujeitos e sobre as políticas que respaldavam a escolarização dos alunos com deficiência. (Diário de campo, 2012) ${ }^{4}$

A cultura escolar comporta uma variedade de apostas em relação aos alunos e alunas com deficiência. No excerto de diário de campo acima, deparamo-nos com uma posição docente que traz descrédito em relação à possibilidade de aprendizagens de uma aluna. Tal como anotado no diário, nos indagamos acerca da formação docente, que pode simplesmente não ter existido para o tema da deficiência e da educação especial. Numerosos fatores podem levar professores e professoras a desacreditar das possibilidades de aprendizagem: falta de recursos, formação docente precária no tema, sobrecarga de trabalho, falta de apoio técnico e pedagógico na produção de atividades, carência de livros e ambientes estimulantes para realizar as aulas etc. A cultura escolar é composta por sucessivos movimentos de aposta nas aprendizagens e no sucesso escolar, combinadas com momentos de desânimo, tendo em vista as dificuldades materiais e sociais das políticas públicas de educação. Há também que

\footnotetext{
${ }^{4}$ Diário de campo do projeto de pesquisa Alunos de Escolas Especiais: Trajetória na Rede Municipal de Ensino de Porto Alegre, mantido pelo autor principal desse artigo. Maiores informações em http://lattes.cnpq.br/7812805801902661.
} 
se considerar o envolvimento de outras redes de cuidado da criança ou jovem com deficiência, como família e amizades. Também entre os alunos, no convívio da sala de aula, há situações que merecem nossa atenção, e que revelam compreensões acerca dos modos de lidar com a deficiência:

Manhã muito agradável, escola de ensino fundamental, municipal, bairro do extremo da zona leste da cidade de Porto Alegre. Estou assistindo a uma aula de História de sexto ano. A classe é composta por predominância de alunos e alunas negros e pardos, das comunidades da vizinhança da escola, quase todas em situação de alguma vulnerabilidade social. Reina agitação na turma quando são devolvidas as provas pelo professor estagiário, um rapaz que os alunos parecem estar gostando muito, pois já me abordaram no pátio da escola perguntando se ele pode ficar dando aulas para a turma até o final do ano, ele até futebol já jogou com os meninos. Um dos alunos apresenta alguma deficiência, bastante visível em seu comportamento, no modo como fala e como os outros o tratam. Devolvidas as provas, o estagiário passou a comentar as respostas, as notas, passando a palavra para uns e outros. Em dado momento, esse aluno com deficiência se manifestou, dizendo o que tinha marcado em certa questão. Um outro aluno, sentado logo na frente dele, perguntou a ele que nota tinha tirado, e ele mostrou a prova. Esse aluno então comentou, em voz alta e clara "tu sempre tira nota dez, em todas as provas", e outro comentou "tudo que ele faz os professores dão dez para ele". O menino com deficiência não demonstrou nenhum incômodo com o comentário, mas o estagiário sim. Ele tomou a prova do aluno com deficiência, mostrou que ela era diferente das demais provas, adequada ao seu nível, e que ele tinha acertado tudo. $O$ que para os demais alunos poderia parecer uma prova simples, para aquele aluno não era. Mesmo assim, alguns alunos insistiram dizendo que "os outros professores faziam tudo igual, e bastava ele escrever alguma coisa na prova e já davam dez para ele". O estagiário narrou então que tem uma irmã com deficiência (fato que eu desconhecia), e a partir dali muitos comentaram vivenciar situação de proximidade com crianças e adultos com alguma deficiência. (Diário de campo, 2017) ${ }^{5}$

Com base no relato supracitado, compreende-se que a escola é um espaço sociocultural no qual a relação dos alunos com o estudo encontra sentido na praticidade da situação. Isso significa dizer que o conhecimento de cada sujeito não se restringe ao acúmulo de informações ou se finda nos parâmetros engessados de avaliação. Portanto, compreender culturalmente a escola é levar em conta seu dinamismo, suas relações sociais, sua diversidade. Em outros termos, é inserir o indivíduo (seja o aluno ou a aluna, o professor ou a professora, as funcionárias da merenda etc.) num papel de tramas que fazem da instituição um local de amplas trocas e negociações sociais (DAYRELL, 2001). Dito isso, pondera-se

${ }^{5}$ Diário de campo do projeto de pesquisa Investigação das aprendizagens de estagiários na produção de atividades didáticas e na relação com as culturas juvenis a partir dos relatórios de estágio docente em Ensino de História, mantido pelo segundo autor desse artigo. Maiores informações em http://lattes.cnpq.br/2541553433398672. 
que, no tocante às pessoas com deficiência, a escola não deve se furtar de compreendê-las como sujeitos que podem sobrepujar os contornos de um currículo individualista. Pelo contrário, deve intentar uma educação que admita as potencialidades e as possibilidades de aprendizado daqueles sujeitos. Sendo assim, é preciso perceber que o jovem com deficiência compartilha do mesmo universo cultural do aluno dito normal, mesmo que no percurso de sua história o roteiro tenha sido escrito de forma diferente.

Em linhas mais gerais, no contexto da cultura escolar, é necessário conceber a escola como parte de uma unidade complexa que compartilha, entre seus diferentes sujeitos, singularidades atinentes a um processo histórico-institucional que põe em funcionamento toda uma rede de ensino. Do mesmo modo, entende-se que, nesse universo de pluralidade, os professores e as professoras devem, além de se apropriarem do conhecimento acerca da deficiência, fomentar espaços de diálogos nos quais docentes e estudantes possam refletir sobre como são afetados pela convivência com as pessoas com deficiência (SAMPAIO; SAMPAIO, 2009). Em um sentido mais amplo, o que está em jogo é enxergar o outro não pelo prisma de uma pretensa anormalidade, mas percebê-lo para além de suas próprias limitações. Limitações, aliás, todos e todas temos. Se agora não temos, em algum momento da vida teremos ou poderemos vir a ter. Essas limitações dizem respeito também à maneira como apreendemos o outro dentro do contexto da escola e nos diferentes espaços de socialização. Desse modo, considerando-se a perspectiva da cultura escolar, imbricam-se os modelos médico e social de deficiência de forma a salientar que estrutura e processo interagem em confluência e não em linearidade. Portanto, a relação entre ambos se dá em um movimento de reciprocidade do qual fazem parte, professores e professoras, alunos e alunas, as família, demais pessoas da comunidade escolar e a sociedade em geral, que pode não estar presente fisicamente na sala de aula, mas lá está pela via de suas representações simbólicas e culturais. Fica o desafio de produzir aprendizagens em terreno com tantas contingências, mas certamente em uma escola que vai fazer diferença na vida de todos e todas.

\section{REFERÊNCIAS}

ALEM, N. C. Breve análise do atual modelo social de deficiência. In: Anais do SEMINÁRIO INTERNACIONAL SOBRE OS DIREITOS HUMANOS DAS PESSOAS COM DEFICIÊNCIA, 2015, São Paulo. São Paulo: EDEPE, 2015.

AUGUSTIN, I. Modelos de deficiência e suas implicações na educação inclusiva. In.: Anais do IX SEMINÁRIO DE PESQUISA EM EDUCAÇÃO DA REGIÃO SUL DA ASSOCIAÇÃO NACIONAL DE PÓS-GRADUAÇÃO EM EDUCAÇÃO (ANPED SUL), 9, 2012. Caxias do Sul: UCS, 2012. 
BAMPI, L. N. S.; GUILHEM, D.; ALVES, E. D. Modelo social: uma nova abordagem para o tema deficiência. Revista Latino-Americana de Enfermagem [on-line], v. 18, n. 4, p. 816-823, 2010. ISSN 1518-8345.

BARBOSA-FOHRMANN, A. P. Os modelos médico e social de deficiência a partir dos significados de segregação e inclusão nos discursos de Michel Foucault e de Martha Nussbaum. Revista Estudos Institucionais, v. 2, n. 2, p. 736-755, 2016.

BISOL, C. A.; PEGORINI, N. N.; VALENTINI, C. B. Pensar a deficiência a partir dos modelos médico, social e pós-social. Cadernos de Pesquisa, v. 24, n. 1, p. 87-100, jan./abr. 2017.

BONFIM, S. M. M. A luta por reconhecimento das pessoas com deficiência: aspectos teóricos, históricos e legislativos. 2009. Dissertação (Mestrado em Ciência Política) - Instituto Universitário de Pesquisas do Rio de Janeiro. 214 f.

DAYRELL, J. A escola como espaço sociocultural. In: DAYRELL, J. (Org.). Múltiplos olhares sobre educação e cultura. 2. reimp. Belo Horizonte: Ed. UFMG, 2001. p. 136-161.

DINIZ, D. O que é deficiência. Col. Primeiros Passos. São Paulo: Editora Brasiliense, 2007.

DINIZ, D.; SANTOS, W. Deficiência, direitos humanos e justiça. In.: DINIZ, D.; SANTOS, W. (Orgs.). Deficiência e Discriminação. Letras Livres: Brasília, 2010. p. 97-115.

DINIZ, D.; BARBOSA, L.; SANTOS, W. R. Deficiência, direitos humanos e justiça. Sur: Revista Internacional de Direitos Humanos [on-line], v. 6, n. 11, p. 64-77, ago. 2009. ISSN 1806-6445. DOI: http://dx.doi.org/10.1590/S1806-64452009000200004.

FRANÇA, T. H. Modelo social de deficiência: uma ferramenta sociológica para a emancipação social. Revista Lutas Sociais, v. 17, n. 31, p. 59-73, jul./dez. 2013.

FRENCH, S.; DEPOY, E. Multiculturalism and Disability: a critical perspective. Disability and Society, v. 15, n. 2, p. 207-218, 2000.

GAIO, R. Para além do corpo deficiente: histórias de vida. Jundiaí: Fontoura, 2006.

JULIA, D. A cultura escolar como objeto histórico. Revista Brasileira de História da Educação, n. 1, p. 9-43, 2001. Disponível em: http://periodicos.uem.br/ojs/index.php/rbhe/article/view/38749/20279. Acesso em: 12 de jun. 2020.

KASSAR, M. C. M. Marcas da história social no discurso de um sujeito: uma contribuição para a discussão a respeito da constituição social da pessoa com deficiência. Cadernos CEDES [online], v. 20, n. 50, p. 41-54, 2000. ISSN 0101-3262.

MELLO, A. G.; NUERNBERG, A. H. Gênero e deficiência: interseções e perspectivas. Revista Estudos Feministas, v. 20, n. 3, p. 635-655, set./dez. 2012.

MELLO, A. G.; NUERNBERG, A. H.; BLOCK, P. Não é o corpo que nos discapacita, mas sim a sociedade: a interdisciplinaridade e o surgimento dos estudos sobre deficiência no Brasil e no mundo. In.: SCHIMANSKI, E. D.; CAVALCANTE, F. G. (Orgs.). Pesquisa e extensão: experiências e perspectivas interdisciplinares. Editora UEPG: Ponta Grossa, 2014. 1. ed. 260p. p. 91-118.

MELO, T. D. de. O modelo médico e sua importância para a inclusão social da pessoa com deficiência no Brasil. Revista Científica Multidisciplinar Núcleo do Conhecimento, ano 04, ed. 07, v. 12, p. 169-179, jul. 2019. ISSN: 2448-0959 
MENDES JUNIOR, Edson Mendes; SEFFNER, Fernando. Conexões entre sexualidade e deficiência são desafios para pensar escola diversa e inclusiva. Revista de Estudos Interdisciplinares, $\quad$ v. 1 , p. 86-106, 2020. Disponível em http://www.ceeinter.com.br/ojs/index.php/ceeinter/article/view/46/pdf_22 Acesso em 22 de junho de 2020

MENDES JÚNIOR, E. Alunos de escolas especiais: trajetórias na rede municipal de ensino de Porto Alegre. 2013. Dissertação (Mestrado em Educação) - Universidade Federal do Rio Grande do Sul, Porto Alegre, 2013. $150 \mathrm{f}$.

MENDES JÚNIOR, E.; TOSTA, E. I. L. 50 Anos de Políticas de Educação Especial no Brasil: movimentos, avanços e retrocessos. In.: Anais do IX SEMINÁRIO DE PESQUISA EM EDUCAÇÃO DA REGIÃO SUL DA ASSOCIAÇÃO NACIONAL DE PÓS-GRADUAÇÃO EM EDUCAÇÃO (ANPED SUL), 9, 2012. Caxias do Sul: UCS, 2012.

OLIVEIRA, R. R. R.; MAIO, E. R. Sexualidade e deficiência intelectual: a importância do ensino. In.: II SIMPÓSIO INTERNACIONAL DE EDUCAÇÃO SEXUAL - II SIES: GÊNERO, DIREITOS E DIVERSIDADE SEXUAL: TRAJETÓRIAS ESCOLARES, 2, 2011. Maringá: UEM, 2011.

PESSOTTI, I. Deficiência mental: da superstição à ciência. São Paulo: T. A. Queiroz: Editora da Universidade de São Paulo, 1984.

RECHINELI, A.; PORTO, E. T. R.; MOREIRA, W. W. Corpos deficientes, eficientes e diferentes: uma visão a partir da educação física. Revista Brasileira de Educação Especial [on-line], v. 14, n. 2, p. 293-310, 2008. ISSN 1413-6538. DOI: http://dx.doi.org/10.1590/S141365382008000200010 .

RODRIGUES, N. Artigo 5: igualdade e não-discriminação. In.: DIAS, J. et al. (Orgs.). Novos Comentários à Convenção sobre os Direitos das Pessoas com Deficiência. 3. ed. Brasília, DF: Secretaria de Direitos Humanos da Presidência da República, 2014. p. 52-54

SAMPAIO, C. T.; SAMPAIO, S.M.R. Convivendo com a diversidade: a inclusão escolar da criança com deficiência intelectual. In.: DÍAZ, F. et al. (Orgs.). Educação inclusiva, deficiência e contexto social: questões contemporâneas [on-line]. Salvador: EDUFBA, 2009. p. 71-78. ISBN: 978-85-232-0928-5. Disponível em: http://books.scielo.org/id/rp6gk. Acesso em: 06 jul. 2020.

SANTOS, W. Deficiência, desigualdade e assistência social: o Brasil e o debate internacional. In.: DINIZ, D.; SANTOS, W. (Orgs.). Deficiência e Discriminação. Brasília: Letras Livres, 2010. p. 117-141.

WERNECK, C. Modelo médico x modelo social da deficiência. In.: Manual da mídia legal 3: comunicações pela saúde. Escola de Gente - Rio de Janeiro: WVA Editora, 2004. p. 16-20 